\title{
Characterization of ASCAT measurements based on buoy and QuikSCAT wind vector observations
}

\author{
A. Bentamy ${ }^{1}$, D. Croize-Fillon ${ }^{1}$, and C. Perigaud ${ }^{2}$ \\ ${ }^{1}$ Institut Français pour la Recherche et l'Exploitation de la MER (IFREMER), France \\ ${ }^{2}$ Jet Propulsion Laboratory (JPL/NASA), USA
}

Received: 21 December 2007 - Published in Ocean Sci. Discuss.: 19 March 2008

Revised: 9 June 2008 - Accepted: 20 October 2008 - Published: 11 December 2008

\begin{abstract}
The new scatterometer Advanced SCATterometer (ASCAT) onboard MetOp-A satellite provides surface wind speed and direction over global ocean with a spatial resolution of $25 \mathrm{~km}$ square over two swaths of $550 \mathrm{~km}$ widths. The accuracy of ASCAT wind retrievals is determined through various comparisons with moored buoys. The comparisons indicate that the remotely sensed wind speeds and directions agree well with buoy data. The root-mean-squared differences of the wind speed and direction are less than $1.72 \mathrm{~m} / \mathrm{s}$ and $18^{\circ}$, respectively. At global scale, ASCAT winds are compared with surface winds derived from QuikSCAT scatterometer. The results confirm the buoy analyses, especially for wind speed ranging between $3 \mathrm{~m} / \mathrm{s}$ and $20 \mathrm{~m} / \mathrm{s}$. For higher wind conditions, ASCAT is biased low. The ASCAT underestimation with respect to QuikSCAT winds is wind speed dependent. The comparisons based on the collocated scatterometer data collected after 17 of October 2007 indicate that there are significant improvements compared to previous periods.
\end{abstract}

\section{Introduction}

Since 1991 scatterometers onboard satellites provide continuously valuable surface wind speed and direction estimates over global ocean. Scatterometer surface wind products are widely used for various scientific and operational purposes. Several authors have established their positive impact in many oceanic and atmospheric fields. For instance, they were used to enhance the determination of the ocean circulation model forcing function at global scale (e.g. Ayina

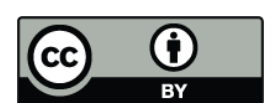

Correspondence to: A. Bentamy (abderrahim.bentamy@ifremer.fr) et al., 2006) as well as at regional scales (e.g. Blank et al., 2005). They were successfully used within assimilation process in numerical weather prediction models (e.g. Figa et al., 2000). Numerous studies demonstrated the positive impact of scatterometer wind retrievals in predicting and describing tropical cyclones (e.g. Le Marshall et al., 2000; Katsaros et al., 2001). All these studies contribute significantly to promote the use of remotely sensed winds and encourage satellite organizations to maintain surface observation systems from scatterometers.

The latest remotely sensed surface wind-measuring instrument is the Advanced SCATterometer (ASCAT). It was launched aboard the European Meteorological Satellite Organization (EUMESAT), MetOp-A on 19 October 2006. Scientific and technical documentation related to ASCAT physical measurements as well as to ASCAT derived products may be found at the EUMETSAT web site http://www.eumetsat.int/Home/Main/Publications/ Technical_and_Scientific_Documentation/Technical_Notes/ index.htm and under EUMETSAT Ocean \& Sea Ice Satellite Application (O\&SI SAF) web site (http://www.osi-saf.org/). MetOp is in a circular orbit (near synchronous orbit) for a period of about $101 \mathrm{~min}$, at an inclination of $98.59^{\circ}$ and at a nominal height of $800 \mathrm{~km}$ with a 29-day repeat cycle. ASCAT has two swaths $550 \mathrm{~km}$ wide, located on each side of the satellite track, separated by $700 \mathrm{~km}$. It operates at $5.3 \mathrm{GHz}$ ( $\mathrm{C}$ band). Its fore-beam and aft-beam antennas point at $45^{\circ}$ and $135^{\circ}$ on each side of the satellite track, respectively. The mid-beam antennas point at $90^{\circ}$. The ASCAT beams measure normalized radar cross sections with vertical polarization, $\sigma^{\circ}$, which are a dimensionless property of the surface, describing the ratio of the effective echoing area per unit area illuminated. The fore and aft-beams provide backscatter coefficient measurements at incidence

Published by Copernicus Publications on behalf of the European Geosciences Union. 
angle varying between $34^{\circ}$ and $64^{\circ}$. The mid-beams provide $\sigma^{\circ}$ measurements at incidence angle varying between $25^{\circ}$ and $53^{\circ}$. Backscatter coefficients are provided with two spatial resolutions of $25 \mathrm{~km}$ and $12.5 \mathrm{~km}$ over the global ocean.

Since 20 March 2007, the Royal Netherlands Meteorological Institute (KNMI) processes and makes available surface wind vector data derived from ASCAT backscatter coefficients (http://www.knmi.nl/scatterometer/publications/pdf/ ASCAT_Product_Manual.pdf). The ASCAT swath datasets used in this study are referenced as ASCAT level $2 b$ (L2b) products. ASCAT wind retrievals are provided at each scatterometer wind vector cell (WVC) of $25 \mathrm{~km}$ by $25 \mathrm{~km}$. There are $42 \mathrm{WVC}$ across the two-scatterometer swaths. Data include wind retrievals as well as backscatter coefficients measured over ocean and several associated fields at each valid WVC. Wind data may be discarded if the number of good ASCAT $\sigma^{\circ}$ is quite poor for wind estimation, the KNMI or variational quality control fail, or if the $\mathrm{WVC}$ is land or ice contaminated. Each valid WVC contains two wind vector solutions. The latter are ranked according to the maximumlikelihood estimator associated to the cost function minimizing the difference between measured and predicted based on the empirical CMOD5 (Hersbach et al., 2007) backscatter coefficients. The solution selection is performed based on the 2D-VAR method (Stoffelen et al., 2002).

ASCAT wind products were declared pre-operational on 10 October 2007 at the end of the scatterometer calibration experiment using a ground transponder. ASCAT backscatter coefficients (L1b product) were corrected and winds were processed accordingly. The latter were declared pre-operational on 17 October 2007 (http://www.knmi.nl/ scatterometer/).

ASCAT wind retrievals are expected to be used in order to enhance the spatial and temporal resolutions of surface winds at global and regional scales allowing better characterization of the air-sea interaction process as well as ocean wind forcing. Such a purpose requires the knowledge of ASCAT wind quality at various scales and the characterization of the related errors. Previous studies showed that comparisons between the remotely sensed and buoy winds yield to assess the quality of scatterometer retrievals (e.g. Bentamy et al., 1998; Ebuchi et al., 2002; Pickett et al., 2003). The main objective of this study is to analyze the ASCAT measurements using similar comparison approaches. The former are compared to data from the main buoy networks from March to October 2007. At global scale, the ASCAT winds are compared to wind retrieved from SeaWinds scatterometer onboard QuikSCAT satellite (JPL, 2006) and from the European Centre of Medium Weather Forecasts (ECMWF) wind analysis.

\section{Collocated data}

The investigation of the ASCAT wind quality are mainly based on the use of data collocated in space and time between ASCAT and "reference" sources such as moored buoys, QuikSCAT, and ECMWF.

Buoy data come from the National Data Buoy Center (NDBC) located along the coast of United States of America, the Tropical Atmosphere Ocean (TAO) located in the Equatorial Pacific array, and from Météo-France and UK Met office (MF-UK) located off the English, Ireland, and French coasts. During March-October 2007 the number of available NDBC, TAO, and MF-UK buoys are 34, 5, and 9, respectively. The quite small number of TAO buoys is related to the use of high-resolution wind measurements. The latter are available only as off-line data. NDBC and MF-UK provide hourly data, while TAO provide 10 -min measurements. The latter are temporally averaged to estimate hourly buoy parameters. The buoy data include wind speed at the anemometer height, wind direction (or the corresponding zonal and meridional wind components), sea surface and air temperatures, and relative humidity (or dew point). As the ASCAT wind retrievals correspond to wind observations at 10$\mathrm{m}$ above the ocean surface, the buoy winds are converted to 10-m height using (1/7) power expression (Hakeem, 1993).

Each ASCAT file provided in near real time by O\&SI SAF includes several parameters corresponding to one-orbit measurements. The WVC times and positions are used to select ASCAT data matching each buoy measurement. Satellite and buoy data pairs are considered collocated when the scatterometer WVC location is within $25 \mathrm{~km}$ of a buoy position and the time difference is less than $1 \mathrm{~h}$. The spatial and temporal collocation criteria are suitable to get reasonable numbers of satellite and buoy matches. They allow quite similar sampling of collocated data between day and night. The resulting collocated datasets involve all selected atmospheric and oceanic buoy measurements and all scatterometer L2b data. The selection of validated buoy data is mainly based on the use of the quality control flags included in buoy files. The examination of the wind vector cell quality flags related to the scatterometer wind retrievals matching buoy winds indicates that only a small portion of flags stating that the wind retrievals are performed nearshore or their values are lower than $3 \mathrm{~m} / \mathrm{s}$ are set to 1 . The rest of WVC quality flags are set to 0 . For comparison purposes, all collocated scatterometer data, including nearshore and low winds, are used in this study to assess the quality of ASCAT retrievals at local scales.

For global scales, the quality of ASCAT data is investigated using QuikSCAT wind observations and ECMWF winds analysis. QuikSCAT data are widely used and therefore considered in this study as a "surface reference". Details about QuikSCAT data and methods used to estimate surface winds from backscatter coefficients could be found in Jet Propulsion Laboratory documentation (JPL, 2006). 
QuikSCAT WVC spatial resolution is $25 \mathrm{~km}$ square over a swath of $1800 \mathrm{~km}$ width. The ascending equatorial times occur approximately at $6 \mathrm{~h}$ a.m $\pm 30 \mathrm{mn}$, and $9 \mathrm{~h} 30 \mathrm{p} . \mathrm{m}$. for QuikSCAT and METOP, respectively. The repeat cycle for ASCAT is 29 days, whereas is 4 days for QuikSCAT scatterometer. The collocation of scatterometer data is achieved by selecting all QuikSCAT scatterometer observations acquired within $4 \mathrm{~h}$ and $50 \mathrm{~km}$ of each ASCAT WVC (ASCAT and QuikSCAT being valid). As expected, the spatial distribution of match-up number is highly related to a combination of orbit phasing and swath width. On average, 4 pairs per each 0.25 degree grid point are found, with a maximum located at the high latitudes and especially in the southern hemisphere and in the Atlantic and Indian oceans. Only a small percentage (about 10\%) of collocated ASCAT and QuikSCAT data occur within $1 \mathrm{~h}$ and mostly at high latitudes. The mean value of spatial separation between ASCAT and QuikSCAT scatterometers is about $25 \mathrm{~km}$. The lowest values are obtained in middle and high latitudes. For this study, only the closest QuikSCAT scatterometer and ASCAT cells are used.

ECMWF wind analyses are available four times a day (00:00; 06:00; 12:00; 18:00 UTC) on regular grid over the global ocean with a spatial resolution of $0.50^{\circ}$ in longitude and latitude. The wind analysis is interpolated in space and time over ASCAT and QuikSCAT swaths using a bilinear method.

\section{Results}

\subsection{Data coherency}

Prior any wind inter-comparisons, the collocated pairs are used to assess the coherency between ASCAT and buoy as well as between ASCAT and QuikSCAT data. The topic is to investigate the ability of buoy surface wind measurements or QuikSCAT wind observations to retrieve the main characteristics of ASCAT backscatter coefficient measurements.

The dependence of the radar returns on the surface wind vector is generally specified by Eq. (1). Previous studies indicate that four or five coefficients would improve the fit to the azimuthal modulation of $\sigma^{\circ}$ (Pierson, W. J.: A note of the modulation of radar backscatter as a function of wind direction, personal communication, 1992.). However, we solely specified the C-band radar echo by the following second order truncated Fourier expression:

$\sigma^{\circ}=A 0+A 1 \cos \chi+A 2 \cos 2 \chi$

The coefficient $A 0$, referred as the power coefficient, mainly carries the information on wind speed. The harmonic coefficient $A 1$ describes the upwind and downwind asymmetry. The coefficient $A 2$ describes the difference in backscatter coefficient extrema. These coefficients are functions of wind speed, incidence angle and polarization.
The estimation of $A 0, A 1$ and $A 2$ may be provided by the following formulas:

$$
\begin{aligned}
& A 0=\left(\sigma_{u}^{\circ}+\sigma_{d}^{\circ}+2 \sigma_{c}^{\circ}\right) / 4 \\
& A 1=\left(\sigma_{u}^{\circ}-\sigma_{d}^{\circ}\right) / 2 \\
& A 2=\left(\sigma_{u}^{\circ}+\sigma_{d}^{\circ}-2 \sigma_{c}^{\circ}\right) / 4
\end{aligned}
$$

$\sigma^{\circ}{ }_{u}, \sigma^{\circ}{ }_{d}, \sigma^{\circ}{ }_{c}$ are the upwind $\left(\chi=0^{\circ}\right)$, downwind $\left(\chi=180^{\circ}\right)$ and crosswind $\left(\chi=90^{\circ}\right.$ or $\left.270^{\circ}\right)$ values of the backscatter coefficient.

The collocated NDBC, TAO, and MF-UK wind directions are used to estimate the model coefficients (Eqs. 2, 3, and 4) for various buoy wind speed and ASCAT beam incidence angle ranges. The upwind, downwind and crosswind cases are collected into two-dimensional bins defined by $1 \mathrm{~m} / \mathrm{s}$ ranges of the buoy wind speed, and by $0.2^{\circ}$ ranges for each ASCAT antenna incidence angle. For our investigation, we use the bins for which the number of samples exceeds 10 . One can notice that buoy anemometer data are used as truth surface winds. Previous studies (e.g. Freilich et al., 1997) based on the comparisons between buoy and satellite data, indicated that the buoy errors contributing to random component errors are about $1-2 \mathrm{~m} / \mathrm{s}$. The propagation of such buoy wind errors in $A 0, A 1$, and $A 2$ estimation is investigated through the assumption of isotropic random component errors of $1 \mathrm{~m} / \mathrm{s}$ in zonal and meridional buoy wind components. Specifically, the GMF coefficients are derived from the Eqs. (2) through (4) using collocated buoy wind ranges.They are considered as "true" coefficients. Adding random component errors in the hourly buoy wind data, a set of $A 0, A 1$, and $A 2$ are determined and considered as "estimated" coefficients. The true and estimated GMF coefficients are compared for various wind speed and ASCAT incidence angle ranges. Table 1 provides the mean of the relative differences between "true" and "estimated" coefficients for the three ASCAT beams and for three buoy wind speed bins. It is found (not shown) that the differences do not exhibit any significant incidence angle dependency. On average, there is no evidence of wind error impact on $A 0$ estimation. The relative differences do not exceed $2 \%$ and are quite similar for the three ASCAT beams. Table 1 indicates that $A 1$ and $A 2$ estimations are more sensitive to wind error, especially for low wind speed range. The latter result is mainly related to the scatterometer measurement physics (Plant, 2000), to wind direction accuracy, and to the small differences between upwind and downwind and between upwind and crosswind backscatter coefficients during light surface winds. The $A 0, A 1$, and $A 2$ changes with respect to buoy wind representativeness error does not effect significantly their behaviours as a function of incidence angle and wind speed. Indeed, the correlation (not shown) between "true" and "estimated" GMF coefficients lies between 0.84 and 0.99 .

In this study, the use of $A 0, A 1$, and $A 2$ aims to assess the ability of buoy surface winds to retrieve some backscatter coefficient characteristics through the GMF coefficient 
Table 1. Mean of relative difference between "true" and "estimated" $A 0, A 1$, and $A 2$ for three buoy wind speed ranges and for the three ASCAT beams.

\begin{tabular}{rrrr|rrr|rrrr}
\hline & \multicolumn{3}{c}{ Fore-beam } & \multicolumn{3}{c}{ Mid-beam } & \multicolumn{3}{c}{ Aft-beam } \\
\hline & $3 \mathrm{~m} / \mathrm{s}$ & $8 \mathrm{~m} / \mathrm{s}$ & $12 \mathrm{~m} / \mathrm{s}$ & $3 \mathrm{~m} / \mathrm{s}$ & $8 \mathrm{~m} / \mathrm{s}$ & $12 \mathrm{~m} / \mathrm{s}$ & $3 \mathrm{~m} / \mathrm{s}$ & $8 \mathrm{~m} / \mathrm{s}$ & $12 \mathrm{~m} / \mathrm{s}$ \\
\hline$A 0$ & 0.01 & 0.00 & 0.01 & 0.01 & 0.00 & 0.02 & 0.01 & 0.00 & 0.01 \\
$A 1$ & 0.14 & 0.10 & 0.01 & 0.06 & 0.04 & 0.04 & 0.10 & 0.00 & 0.18 \\
$A 2$ & 0.04 & 0.05 & 0.09 & 0.18 & 0.01 & 0.01 & 0.21 & 0.04 & 0.01 \\
\hline
\end{tabular}
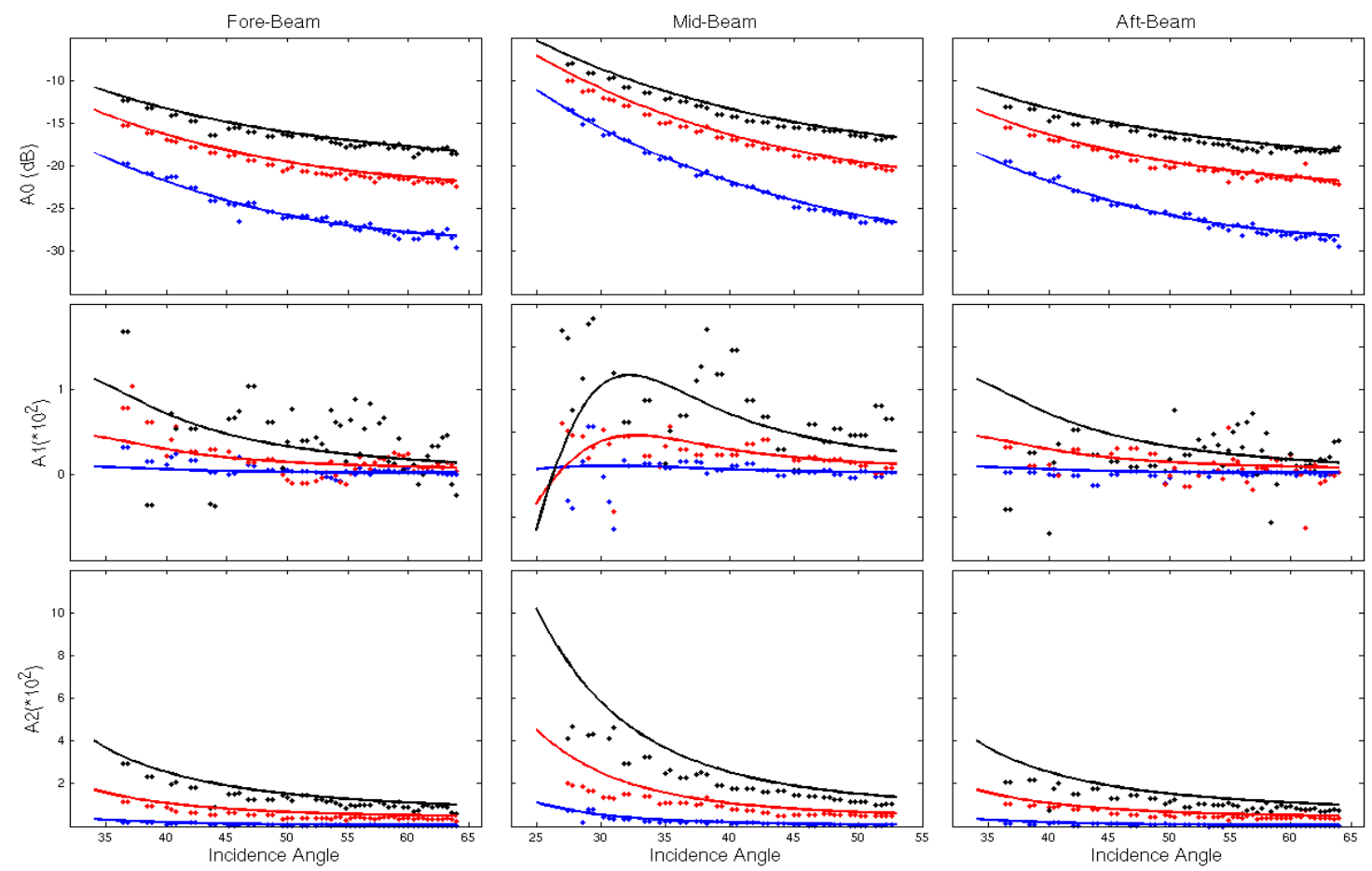

Fig. 1. Behaviors of predicted (full line) and estimated (dots) $A 0$ (1st row), $A 1$ (2nd row), and $A 2$ (3rd row) estimated for three buoy wind speed $1 \mathrm{~m}$ bin: $3 \mathrm{~m} / \mathrm{s}$ (in red), $8 \mathrm{~m} / \mathrm{s}$ (in red), and $12 \mathrm{~m} / \mathrm{s}$ (in black), from CMOD5 model and from collocated ASCAT backscatter coefficients as a function of ASCAT fore- (1st column), mid- (2nd column), and aft-beam (3rd column) incidence angles.

behaviours. Figure 1 shows the behaviors of $A 0, A 1$, and $A 2$ coefficients as a function of ASCAT fore-beam (1st column), mid-beam ( 2 nd column), and aft-beam (3rd column) incidence angles $(\theta)$. The former are represented by symbols (dots), corresponding to three buoy wind speed ranges ( $3 \mathrm{~m} / \mathrm{s}$ in blue, $8 \mathrm{~m} / \mathrm{s}$ in red, and $12 \mathrm{~m} / \mathrm{s}$ in black), and are compared to predictions from C-band model CMOD5 (full line). The estimated and predicted $A 0$ as well as $A 2$ coefficients exhibit very similar behaviors. They increase with wind speed and decrease with incidence angle with similar gradient shape. The statistical tests confirm that their distributions are comparable at level $95 \%$. The main discrepancies are found for $A 1$ coefficient representing the upwind/downwind asymmetry (see Eq. 4). Indeed, the estimated $A 1$ exhibit much more scattering than $A 0$ and $A 2$ yielding to some poor comparisons to the predicated $A 1$ coefficients. However, both predicted and estimated indicate that the differences between upwind and downwind $\sigma^{\circ}$ are quite small and are in general positive for incidence angles greater than $30^{\circ}$. A1 increases with $\theta$ up to a maximum located between $32^{\circ}$ and $38^{\circ}$ depending on the wind speed ranges. Afterward $A 1$ decreases with increasing $\theta$.

ASCAT and QuikSCAT data coherency is also investigated based on the approach described above and similar results are found (not shown). These results suggest that the ASCAT $\sigma^{\circ}$ are highly related to the wind vector measured by the moored buoys and retrieved from QuikSCAT measurements. Therefore, buoy and QuikSCAT wind data can be used to estimate the quality of ASCAT wind retrievals. 
Table 2. Summary of comparisons between buoy and ASCAT wind data during March-October 2007 period.

\begin{tabular}{|c|c|c|c|c|c|c|c|c|}
\hline & \multirow[t]{2}{*}{ Wind Speed Range } & \multirow[t]{2}{*}{ Length } & \multicolumn{3}{|c|}{ Wind Speed } & \multicolumn{3}{|c|}{ Wind Direction } \\
\hline & & & $\begin{array}{l}\text { Bias } \\
(\mathrm{m} / \mathrm{s})\end{array}$ & $\begin{array}{c}\mathrm{Rms} \\
(\mathrm{m} / \mathrm{s})\end{array}$ & $\rho$ & $\begin{array}{r}\text { Bias } \\
(\operatorname{deg})\end{array}$ & $\begin{array}{r}\text { Std } \\
(\mathrm{deg})\end{array}$ & $\rho^{2}$ \\
\hline \multirow[t]{4}{*}{ NDBC/ASCAT } & ALL & 45383 & 0.10 & 1.72 & 0.94 & 0 & 18 & 1.91 \\
\hline & $<5$ & 15716 & -0.18 & 1.14 & 0.76 & 0 & 27 & 1.70 \\
\hline & $5-10$ & 23768 & 0.20 & 1.13 & 0.83 & 0 & 12 & 1.91 \\
\hline & $\geq 10$ & 5899 & 0.47 & 1.48 & 0.87 & 0 & 10 & 1.94 \\
\hline \multirow[t]{4}{*}{ TAO/ASCAT } & $\bar{A} L L$ & 3447 & 0.39 & 0.79 & 0.92 & 1 & 16 & 1.77 \\
\hline & $<5$ & 691 & -0.08 & 0.71 & 0.76 & -1 & 26 & 1.40 \\
\hline & $5-10$ & 2547 & 0.43 & 0.65 & 0.87 & -2 & 13 & 1.77 \\
\hline & $\geq 10$ & 209 & 1.38 & 0.78 & 0.58 & 2 & 13 & 1.54 \\
\hline \multirow[t]{4}{*}{ UKMF/ASCAT } & ALL & 10276 & -0.07 & 1.54 & 0.88 & 0 & 16 & 1.92 \\
\hline & $<5$ & 3136 & -0.88 & 1.68 & 0.61 & 0 & 25 & 1.73 \\
\hline & $5-10$ & 5039 & 0.13 & 1.13 & 0.77 & 1 & 11 & 1.92 \\
\hline & $\geq 10$ & 2101 & 0.65 & 1.13 & 0.86 & 0 & 9 & 1.95 \\
\hline
\end{tabular}

\subsection{ASCAT and buoy wind comparisons}

The scatterometer and buoy are inter-compared using all collocated data and during the period March-October 2007. The statistics describing the comparisons include conventional and linear moments, characterizing the differences between buoy and scatterometer wind data, and the regression parameters. For instance, Table 2 provides the mean difference (bias), the root mean square difference (rms), the standard deviation (std) difference, the wind speed scalar correlation $(\rho)$, and the vector correlation $\left(\rho^{2}\right)$. The calculation of $(\rho)$ includes the signal-to-noise correlation dependency (Wilks, 1995).

The overall statistical parameters indicate that buoy and ASCAT wind speeds and directions compare well. Indeed, the correlation coefficients are higher than 0.88 and 1.77 for wind speed and direction, respectively. The wind speed differences are characterized by rather small bias (less than $0.50 \mathrm{~m} / \mathrm{s}$ ) and rms (less than $2 \mathrm{~m} / \mathrm{s}$ ) values. The symmetrical regression parameters (not shown) are ranged between 0.93 and 1.03 stating that buoy and scatterometer wind speeds correlate closely. The highest discrepancies between in-situ and the remotely sensed wind data are found for buoy low and/or calm winds (less than $5 \mathrm{~m} / \mathrm{s}$ ). They are more pronounced for buoy wind speed lower than $3 \mathrm{~m} / \mathrm{s}$ (not shown). Table 2 indicates the significant decreasing of correlation coefficients for wind speed as well as for wind direction compared to the statistics estimated for buoy winds higher than $5 \mathrm{~m} / \mathrm{s}$. The corresponding symmetrical regression coefficients increase to 1.26 for NDBC and TAO, and to 1.55 for MF-UK comparisons. These lower results may have several sources: the spatial and temporal variations of low winds over WVC of $25 \mathrm{~km} \mathrm{~s}$ square and during a time interval of $1 \mathrm{~h}$ (collocation criteria), the microwave backscatter detection over the noise level is less accurate at low wind condition (Plant, 2000), and the accuracy of the backscatter empirical model CMOD5 (Hersbach et al., 2007).

To highlight the impact of the temporal wind variability on buoy and scatterometer comparison results, only hourly NDBC data collected during the study period are used to calculate the scatter index (SI: standard deviation divided by the mean of the measurements), and the wind steadiness coefficient (WSC: ration between the mean vector and the mean scalar wind speed). SI provides indications about typical scatter around the mean, while WSC provides information about persistent wind regimes. The latter varies between 0 (wind directions are randomly changing) and 1 (wind directions are steady). The estimated SI values are $0.40,0.19$, and 0.14 for low $(<5 \mathrm{~m} / \mathrm{s})$, medium $(5 \mathrm{~m} / \mathrm{s}-10 \mathrm{~m} / \mathrm{s})$, and high wind $(>10 \mathrm{~m} / \mathrm{s})$ conditions, respectively. The corresponding WSC values are $0.06,0.10$, and 0.31 . Obviously, the highest temporal variability for wind speed and direction is clearly found for low winds. Such variability, not considered in the collocation procedure, may have significant impact on the difference between two wind datasets one hour separated. For instance, the investigation of the wind direction differences between two wind data derived from the same buoy and separated by $1 \mathrm{~h}$ indicate that the related standard deviation (std) is about $46^{\circ}$ for buoy wind speed lower than $3 \mathrm{~m} / \mathrm{s}$, and $17^{\circ}$ for $3 \mathrm{~m} / \mathrm{s}-5 \mathrm{~m} / \mathrm{s}$ wind range. The std values drop to $11^{\circ}$ and to $8^{\circ}$ for medium and high wind conditions, respectively.

Most of collocated buoy data are less than $20 \mathrm{~km}$ from ASCAT WVC locations, suggesting that the spatially separation may have significant influence on the comparison results. To assess this statement, the spatial separation impact is investigated through the use of ASCAT data. As mentioned above, ASCAT WVC spatial resolution is $25 \mathrm{~km}$ 

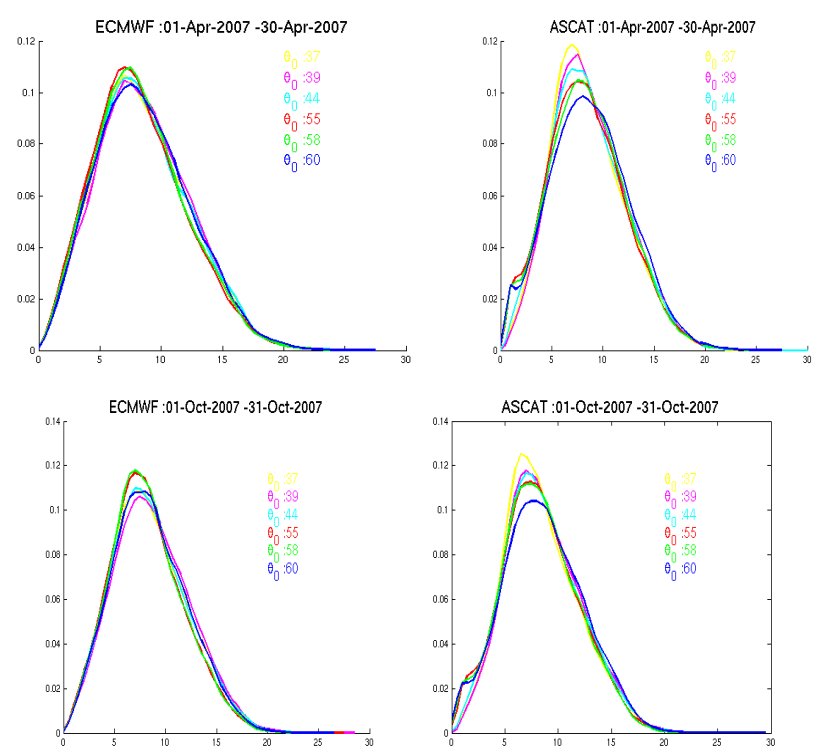

Fig. 2. Wind Speed Distributions (PDF) estimated for six ASCAT fore-beam incidence angles over global ocean from collocated ECMWF (left) and ASCAT (right) during April (first row) and October (second row) 2007.

square. Over each ASCAT swath, the WVC are classified as a function of spatial separation from the neighborhood WVC and wind conditions (low, medium, and high). The temporal separation between two selected WVC is considered as negligible. Thousands of such WVC pairs are collocated over global ocean and during April 2007. Their agreements are characterized by the rms differences and the correlation coefficient as a function of spatial separation and wind speed ranges. For spatial separation of $25 \mathrm{~km}$ and low wind conditions $(<5 \mathrm{~m} / \mathrm{s})$, the correlation coefficients (resp. rms differences) are 0.84 (resp. $0.74 \mathrm{~m} / \mathrm{s}$ ), 0.93 (resp. $1.03 \mathrm{~m} / \mathrm{s}$ ), and 0.86 (resp. $1.10 \mathrm{~m} / \mathrm{s}$ ), for wind speed, zonal and meridional components, respectively. Better results are found for medium and high winds. For instance, for wind speed varying between $5 \mathrm{~m} / \mathrm{s}$ and $10 \mathrm{~m} / \mathrm{s}$, the correlation coefficients (resp. rms differences) are 0.91 (resp. $0.61 \mathrm{~m} / \mathrm{s}$ ), $0.98($ resp. $0.99 \mathrm{~m} / \mathrm{s}), 0.97$ (resp. $1.17 \mathrm{~m} / \mathrm{s})$. These results suggest clearly that a part of the difference between buoy and scatterometer winds are strongly related to the natural variability of surface winds (especially low and calm winds) over the area separating the buoy and WVC locations.

\subsection{ASCAT, QuikSCAT, and ECMWF wind comparisons}

As mentioned above, ASCAT wind production was declared pre-operational on 17 October 2007. Therefore, the comparisons are performed during two periods: 1-30 April 2007 and 17 October-30 November 2007 corresponding to the demonstration and pre-operational modes, respectively. The ASCAT data related to the second period involves several
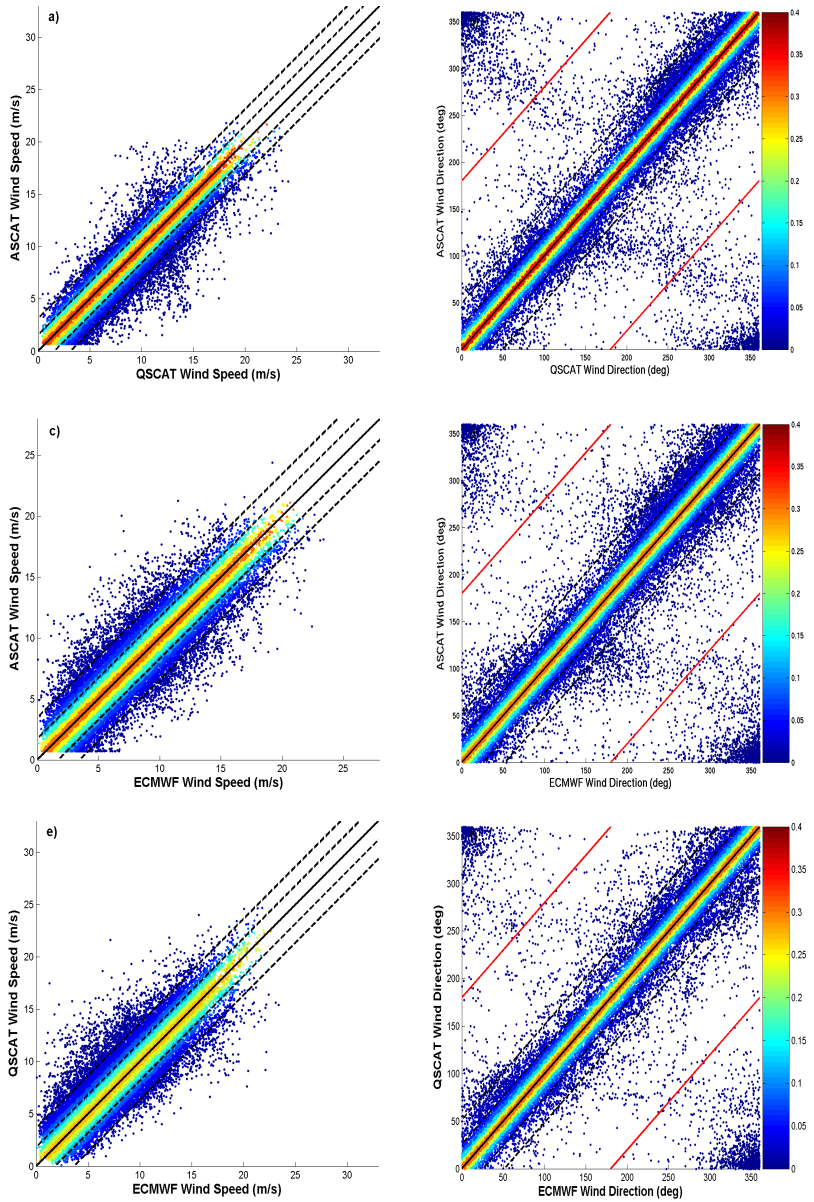

Fig. 3. Scatterplots of wind speeds (left column) and directions (right column) derived from QuikSCAT and ASCAT (top), ECMWF and ASCAT (middle), and from ECMWF and QuikSCAT (bottom).

improvements and corrections with respect to data processed during the first period. For instance, Fig. 2 shows the histograms of wind speed from collocated ASCAT and ECMWF. They are estimated for various ASCAT incidence angles over global ocean. They are normalized to correspond to probability functions (pdf). As expected, the ECMWF wind distributions do not exhibit any systematic relationship to the incidence angles. Whereas, during April 2007 the ASCAT distribution varies with incidence angles. The ASCAT wind speed pdf pick decreases as a function of incidence angle. Even thought similar results are found for ASCAT wind speed pdfs during October-November 2007, the dependency seems less pronounced.

Figure 3 illustrates the second period comparisons between QuikSCAT and ASCAT, ECMWF and ASCAT, and ECMWF and QuikSCAT wind speeds and directions, respectively. More than eleven millions of ASCAT and QuikSCAT pairs are collocated and used. On average the collocated 
Table 3. Statistics of the comparisons of QuikSCAT and ASCAT, ECMWF and ASCAT, and ECMWF and QuikSCAT wind speeds and directions during 17 October-30 November 2007. They are estimated over global ocean, North Oceans $\left(30^{\circ} \mathrm{N}-60^{\circ} \mathrm{N}\right)$, Tropical Oceans $\left(10^{\circ} \mathrm{S}-10^{\circ} \mathrm{N}\right)$, and South Oceans $\left(30^{\circ} \mathrm{S}-60^{\circ} \mathrm{S}\right)$.

\begin{tabular}{|c|c|c|c|c|c|c|c|c|c|c|c|c|c|}
\hline & & \multicolumn{3}{|c|}{ Global } & \multicolumn{3}{|c|}{ North Ocean } & \multicolumn{3}{|c|}{ Tropical Ocean } & \multicolumn{3}{|c|}{ South Ocean } \\
\hline & & $\begin{array}{l}\text { QSCAT/ } \\
\text { ASCAT }\end{array}$ & $\begin{array}{l}\text { ECMWF/ } \\
\text { ASCAT }\end{array}$ & $\begin{array}{l}\text { ECMWF/ } \\
\text { QSCAT }\end{array}$ & $\begin{array}{l}\text { QSCAT/ } \\
\text { ASCAT }\end{array}$ & $\begin{array}{c}\text { ECMWF/ } \\
\text { ASCAT }\end{array}$ & $\begin{array}{l}\text { ECMWF/ } \\
\text { QSCAT }\end{array}$ & $\begin{array}{l}\text { QSCAT/ } \\
\text { ASCAT }\end{array}$ & $\begin{array}{c}\text { ECMWF/ } \\
\text { ASCAT }\end{array}$ & $\begin{array}{l}\text { ECMWF/ } \\
\text { QSCAT }\end{array}$ & $\begin{array}{l}\text { QSCAT/ } \\
\text { ASCAT }\end{array}$ & $\begin{array}{c}\text { ECMWF/ } \\
\text { ASCAT }\end{array}$ & $\begin{array}{l}\text { ECMWF/ } \\
\text { QSCAT }\end{array}$ \\
\hline ֻू. & $\bar{X}$ & 0.32 & -0.08 & -0.40 & 0.46 & -0.03 & -0.49 & 0.47 & -0.10 & -0.57 & 0.27 & 0.02 & -0.26 \\
\hline $\bar{n}$ & $\sigma_{X}$ & 1.42 & 1.55 & 1.51 & 1.49 & 1.77 & 1.71 & 1.19 & 1.12 & 1.24 & 1.55 & 1.68 & 1.58 \\
\hline 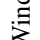 & $a_{S}$ & 0.95 & 1.00 & 1.05 & 0.93 & 0.99 & 1.07 & 0.97 & 1.09 & 1.12 & 0.94 & 0.99 & 1.06 \\
\hline$\vec{g}$ & $\sigma_{D}$ & 17 & 18 & 15 & 18 & 20 & 17 & 18 & 18 & 15 & 17 & 19 & 15 \\
\hline & $\rho^{2}$ & 1.84 & 1.81 & 1.86 & 1.79 & 1.79 & 1.83 & 1.73 & 1.73 & 1.78 & 1.80 & 1.76 & 1.83 \\
\hline
\end{tabular}

data are $25 \mathrm{~km}$ and $3 \mathrm{~h}$ separated in space and time, respectively. However, only $11 \%$ matchups occur within hour and are located north of $50^{\circ} \mathrm{N}$ and south of $40^{\circ} \mathrm{S}$. The temporal separation varies between 3 and $4 \mathrm{~h}$ for $42 \%$ of collocated data. The highest number of collocated data is found at high latitude (especially south $40^{\circ} \mathrm{S}$ ) and the lowest in the equatorial area. Such distributions of the time and space separations may have impact on the scatterometer comparisons. The statistical parameters characterizing the wind speed and direction comparisons performed over the global ocean as well as over some specific oceanic regions are summarized in Table 3. They are calculated from spatial and temporal collocated data during the second period. In general speaking, ASCAT and QuikSCAT wind speeds agree well. Both the correlation and the symmetrical regression coefficients confirm the good agreements between the two sensors. Except in the Tropical area, the correlations exceed 0.90, while the regression coefficients are greater than 0.95 and reaching almost 1.0 in Northern oceans.

The correlation test implies that the correlations coefficients, calculated for global, northern, and southern oceans are not statistically different. The correlation result estimated in the Tropical area is strongly related to the wind speed distribution. Indeed more than $40 \%$ of retrievals are less than $5 \mathrm{~m} / \mathrm{s}$, whereas this percentage is about $17 \%$ over the global ocean. Even though ASCAT and QuikSCAT agree well, the Komogorov-Smirnov test indicates that the null hypothesis stating that the two samples are drawn from the same population may be rejected at 5\% confident level. Indeed, one can notice that QuikSCAT wind speed retrievals are slightly higher than ASCAT estimates. Indeed, the two scatterometer mean wind speed differences are between $0.27 \mathrm{~m} / \mathrm{s}$ (Northern oceans) and $0.47 \mathrm{~m} / \mathrm{s}$ (Tropical oceans). The overall corresponding $\mathrm{rms}$ difference values are less than $2 \mathrm{~m} / \mathrm{s}$. The rms difference involves the impact of atmospheric stability due to the fact that QuikSCAT wind retrievals are reported as the equivalent neutral stability at $10 \mathrm{~m}$ above sea surface, while ASCAT wind data are considered as actual winds at
$10 \mathrm{~m}$ (Chelton et al., 2005). Moreover, the rms difference is not uniform over global ocean. Its spatial patterns estimated during each period (not shown), indicates that the rms in wind speed as well as in wind components are less than $1.4 \mathrm{~m} / \mathrm{s}$ in the trade wind regimes, and ranging between $1 \mathrm{~m} / \mathrm{s}$ and $2.5 \mathrm{~m} / \mathrm{s}$ for wind speed, and between $1.5 \mathrm{~m} / \mathrm{s}$ and $3.5 \mathrm{~m} / \mathrm{s}$ for wind components at high latitudes. Such rms patterns are highly correlated to wind conditions. Indeed, the lowest rms value is found for $6-9 \mathrm{~m} / \mathrm{s}$ range and is about $1.30 \mathrm{~m} / \mathrm{s}$. More than 33\% of ASCAT and QuikSCAT wind retrievals are within this interval. For wind speed ranges greater than $14 \mathrm{~m} / \mathrm{s}$, about $7 \%$ of ASCAT and QuikSCAT winds, the rms differences exceed $2 \mathrm{~m} / \mathrm{s}$.

In order to investigate the difference between wind speed pairings, the mean difference and the corresponding error bars associated to the $90 \%$ confidence limits are calculated using the threshold values of surface wind speed. To avoid the bias inherent to such binning process when calculations are performed versus one wind reference (Freilich, 1997), the difference between QuikSCAT and ASCAT winds (in this order) is estimated according to QuikSCAT and ASCAT wind speed $1 \mathrm{~m} / \mathrm{s}$ bins. Therefore, the difference is significant if the two calculations provide similar trends. The results are presented in Fig. 4a showing the mean wind speed difference and the corresponding error bars in $1 \mathrm{~m} / \mathrm{s}$ intervals of QuikSCAT (full line), and in $1 \mathrm{~m} / \mathrm{s}$ intervals of ASCAT (dashed line). Figure $4 \mathrm{~b}$ shows the sampling length distribution a function of wind speed bins. Only wind speed bins involving more than 100 samples are considered. One can notice that ASCAT and QuikSCAT wind speed distributions are very similar. The main significant departure is found for wind speed exceeding $10 \mathrm{~m} / \mathrm{s}$. Indeed, over this interval QuikSCAT winds are higher than ASCAT retrievals. Over $10-15 \mathrm{~m} / \mathrm{s}$ interval, the differences are of the same order than the overall bias between the scatterometer wind speeds (Table 3). For higher winds, the difference increases faster according to QuikSCAT than ASCAT wind speed ranges. 


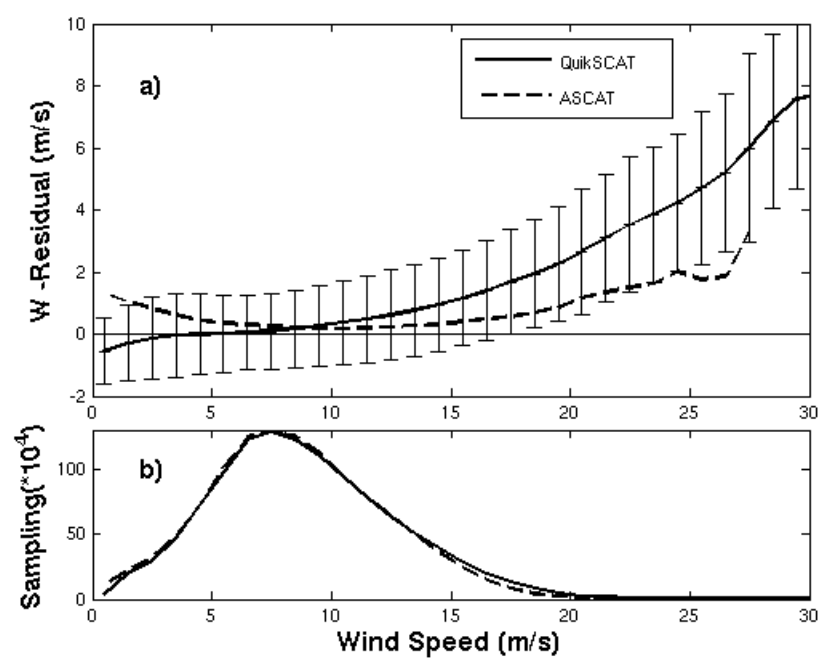

Fig. 4. Behaviour of wind speed residual (QuikSCAT - ASCAT) as a function of QuikSCAT (heavy line), and ASCAT (dashed line) wind speed ranges(top). The bottom figure shows the distribution of the sampling length in each wind speed $1 \mathrm{~m} / \mathrm{s}$ bin.

Similar investigations are performed for wind direction comparisons as a function of ASCAT and QuikSCAT wind speed ranges. Even though the bias exhibits a slight function of wind speed, is small and does not exceed $3^{\circ}$. The main wind speed dependency is found for the standard deviation of wind direction difference (Fig. 5). The highest values are found for low wind speed (less than $5 \mathrm{~m} / \mathrm{s}$ ). This result is quite consistent with buoy comparisons for ASCAT (Sect. 3.2) as well as for QuikSCAT (Ebutchi et al., 2002). It is related to wind direction variability with respect to the spatial and temporal separations, to the low upwind/crosswind modulation of the two scatterometer backscatter measurements, and to the ambiguity removal procedure. The percentage of QuikSCAT and ASCAT wind direction differences exceeding $90^{\circ}$ is ranged between $10 \%$ (winds about $3 \mathrm{~m} / \mathrm{s}$ ) and $28 \%$ (winds about $1 \mathrm{~m} / \mathrm{s}$ ). For wind speeds greater than $6 \mathrm{~m} / \mathrm{s}$, the standard deviation remains lower than $20^{\circ}$ until $20 \mathrm{~m} / \mathrm{s}$. The observed mean difference increasing for wind speed exceeding $20 \mathrm{~m} / \mathrm{s}$ is mainly related to the sampling length. Indeed, the number of matchups collected for such high wind conditions is 16 times lower than for medium wind speeds $(7 \mathrm{~m} / \mathrm{s}-9 \mathrm{~m} / \mathrm{s})$. The percentage of wind direction differences higher than $90^{\circ}$ is about $3.5 \%$ for high winds which is quite similar to the percentage $(3.05 \%)$ found for wind speeds ranging between 3 and $20 \mathrm{~m} / \mathrm{s}$.

The differences between ASCAT and QuikSCAT are related to several parameters such as sea surface state, wind condition, instrumental physics, wind retrieval algorithms, and spatial and temporal separations. Retaining only collocated ASCAT and QuikSCAT wind speeds such as the time difference is less than $1 \mathrm{~h}$ provides some improvements. However, more than $90 \%$ of such data are located north

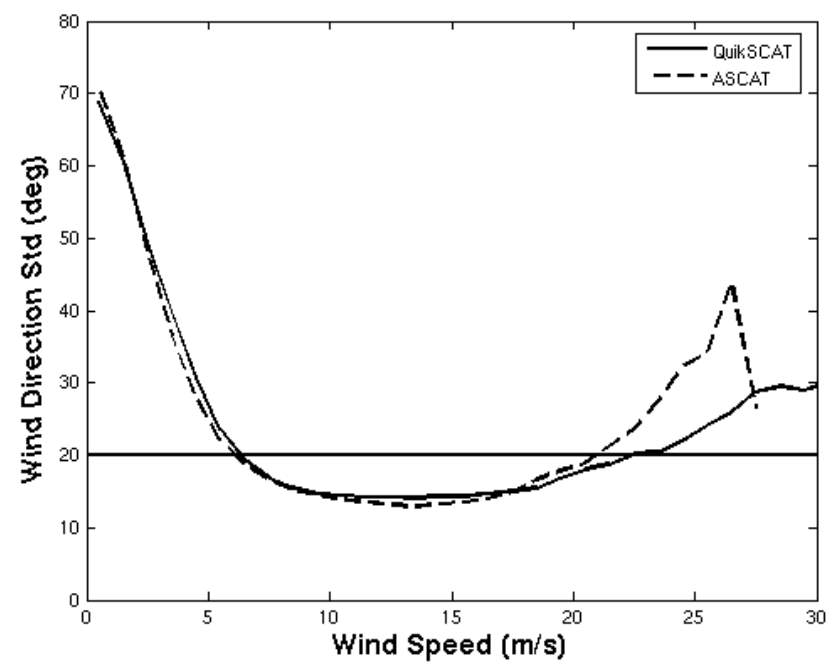

Fig. 5. Standard deviation of wind direction difference between QuikSCAT and ASCAT as a function of QuikSCAT (heavy line) and ASCAT (dashed line) wind speed ranges.

$50^{\circ} \mathrm{N}$ or south $50^{\circ} \mathrm{S}$. No data are found between $10^{\circ} \mathrm{S}$ and $10^{\circ} \mathrm{N}$. The main improvements are found for wind speed ranging between $3 \mathrm{~m} / \mathrm{s}$ and $20 \mathrm{~m} / \mathrm{s}$ (95\% of data). Within the former interval the bias and standard deviation values are reduced to $0.07 \mathrm{~m} / \mathrm{s}$ and to about $1.0 \mathrm{~m} / \mathrm{s}$ for wind speed difference, and to $0^{\circ}$ and $17^{\circ}$ for wind direction difference, respectively. The wind speed correlation and wind direction vector correlation increase to about 0.97 and 1.90, respectively. Such results are quite similar to previous findings related to QuikSCAT and buoy comparisons (Ebuchi et al., 2002). The main discrepancies between QuikSCAT and ASCAT winds are for low and high wind conditions. At wind speeds lower than $3 \mathrm{~m} / \mathrm{s}$, the wind speed and direction correlations decrease to 0.75 and 1.10 . Such results are related to the low wind variability as has been stated from hourly buoy data (see Sect. 3.2). Based on the collocated data separated by less than $1 \mathrm{~h}$, it is found that QuikSCAT provides higher winds than ASCAT. Indeed, ASCAT and QuikSCAT retrievals exceed $20 \mathrm{~m} / \mathrm{s}$ for $0.4 \%$ and $0.8 \%$ of data, respectively. There are 345 ( $0.04 \%$ of data) QuikSCAT collocated speeds exceeding $27 \mathrm{~m} / \mathrm{s}$. The corresponding ASCAT collocated speeds are ranged between $19.26 \mathrm{~m} / \mathrm{s}$ and $26.93 \mathrm{~m} / \mathrm{s}$. The finding differences for high wind conditions may be associated to the results derived from buoy and scatterometer wind comparisons. As stated in Sect. 3.2, ASCAT tend to underestimate high winds. Moreover, for buoy winds exceeding $18 \mathrm{~m} / \mathrm{s}$, the mean difference between buoy and ASCAT winds reaches $1.13 \mathrm{~m} / \mathrm{s}$ with a rms difference of $1.32 \mathrm{~m} / \mathrm{s}$. Similar comparisons are performed from collocated buoy and QuikSCAT data. They indicate for high buoy winds (greater than $18 \mathrm{~m} / \mathrm{s}$ ), QuikSCAT retrievals are overestimated with a bias of $-1.23 \mathrm{~m} / \mathrm{s}$ and rms difference of $1.57 \mathrm{~m} / \mathrm{s}$. Therefore the discrepancy between QuikSCAT and ASCAT observed 
for very high wind speeds should be carefully considered. These differences in wind speeds do not have any significant impact on wind direction comparisons. The statistics are very similar to those found for $3 \mathrm{~m} / \mathrm{s}-20 \mathrm{~m} / \mathrm{s}$ wind speed ranges.

\section{Conclusions}

ASCAT scatterometer on board METOP-A satellite is the first of a series dedicated to provide routinely surface wind observations over global ocean. The retrievals are expected to enhance the determination and the spatial and temporal resolutions of ocean circulation model and ocean wave forcing models. Such topic may be achieved through the use of ASCAT data in combination with available satellite and buoy wind data. Therefore, prior any data merging it is essential to investigate the comparisons between ASCAT retrievals and available wind sources.

The ASCAT wind observations are validated through comparisons with collocated measurements from moored NDBC, MF-UK, and TAO buoys and with global collocations with QuikSCAT scatterometer and ECMWF wind analysis. All buoys, including off-shore and nearshore, and ASCAT data such as the spatial and temporal separations are less than $25 \mathrm{~km}$ and $1 \mathrm{~h}$ are selected. Buoy winds are converted at $10 \mathrm{~m}$ height using power law. Due to the scatterometer orbit characteristics, the temporal separation between ASCAT and QuikSCAT WVC is extended to $4 \mathrm{~h}$ while the spatial separation is limited to $50 \mathrm{~km}$. ECMWF are interpolated in space and time onto ASCAT and QuikSCAT swaths. The selection of valid in-situ as well as remotely sensed winds is based on the use of quality flags involved in data files. Two period comparisons are considered dealing with ASCAT demonstration and pre-operational data modes, respectively.

Buoy as well as QuikSCAT winds are consistent with ASCAT measurements. They both retrieve the main characteristics of corrected ASCAT backscatter coefficients. Therefore, the wind comparisons are performed at local as well as at global scales. They indicate that over the wind speed range $3-20 \mathrm{~m} / \mathrm{s}$ and for temporal separation less than $1 \mathrm{~h}$, the rms differences between buoy and ASCAT as well as between QuikSCAT and ASCAT winds are both about $1 \mathrm{~m} / \mathrm{s}$. The biases exhibit small dependencies on the surface wind speeds lower than $18 \mathrm{~m} / \mathrm{s}$. For the wind direction comparisons, the rms differences are less than $20^{\circ}$ and the biases are quite small and their wind speed dependencies are not significant. Using only buoy and ASCAT matchups, wind speed and direction residuals do not exhibit any significant dependency on sea surface and air temperature. The investigations of the ASCAT ambiguity removal procedure indicate that the skill is greater than $92 \%$. At this stage, it is concluded that ASCAT meet the mission specifications for wind speed and direction.

The main discrepancies between ASCAT and buoy and between ASCAT and QuikSCAT are found out for low and high wind speeds. For instance, selecting ASCAT and QuikSCAT less than $3 \mathrm{~m} / \mathrm{s}$, indicates that the wind speeds still have a good agreement, whereas the wind direction difference exhibits high rms values. The latter are partly related to the spatial and temporal low wind variability, as is stated trough the use of buoy and scatterometer data. For higher winds, ASCAT wind speed retrievals tend to be underestimated mostly with respect to QuikSCAT retrievals. Indeed, QuikSCAT provides almost two times winds exceeding $20 \mathrm{~m} / \mathrm{s}$ than ASCAT. Furthermore, for a small fraction of collocated high winds, QuikSCAT provides wind speeds $7 \mathrm{~m} / \mathrm{s}$ higher than ASCAT retrievals. This high wind speed behavior is an important issue for future investigations.

Acknowledgements. This study is supported by TOSCA CNES program. The authors are grateful to ECMWF, EUMETSAT, CERSAT, GODIVA, JPL, Météo-France, NDBC, O\&SI SAF, PMEL, and UK MetOffice, for providing the buoy, numerical, and satellite data used in this study. I thank Bonekamp and Stoffelen for their helpful comments on this scatterometer analysis.

Edited by: N. Pinardi

\section{References}

Ayina, H.-L., Bentamy, A., Madec, G., and Nuñez, A. M.: The Impact of Satellite Winds and Latent Heat Fluxes in a Numerical Simulation of the Tropical Pacific Ocean, J. Climate, 19(22), 5889-5902, doi:10.1175/JCLI3939.1, 2006.

Bentamy, A., Grima, N., and Quilfen, Y.: Validation of the gridded weekly and monthly wind fields calculated from ERS-1 scatterometer wind observations, Global Atmos. Ocean. System, 6, 373-396, 1998.

Blanke, B., Speich, S., Bentamy, A., Roy, C., and Sow, B.: Modeling the structure and variability of the southern Benguela upwelling using QuikSCAT wind forcing, J. Geophys. Res., 110(C7), C07018, doi:10.1029/2004JC0025292005, 2005.

Chelton, D. B. and Freilich, M. H.: Scatterometer-Based Assessment of 10-m Wind Analyses from the Operational ECMWF and NCEP Numerical Weather Prediction Models, Mon. Weather Rev., 133, 409-429, 2005.

Ebuchi, N., Graber, H. C., and Caruso, M. J.: Evaluation of wind vectors observed by QuikSCAT/SeaWinds using ocean buoy data, J. Atmos. Oceanic Technol., 19, 2049-2069, 2002.

Figa, J. and Stoffelen, A.: On the assimilation of Ku-band scatterometer winds for weather analysis and forecasting, IEE Trans. Geosci. Remote Sens., 38, 1893-1902, 2000.

Freilich, M. H.: Validation of vector magnitude data sets: Effects of random component errors, J. Atmos. Ocean. Tech., 14, 695-703, 1997.

Hakeem, K. J.: Statistical dependencies of sea state characteristics on water temperature and wind-wave age, J. Mar. Sys., 4(2-3), $161-169,1993$.

Hersbach, H., Stoffelen, A., and de Haan, S.: An improved C-band scatterometer ocean geophysical model function: CMOD5, J. Geophys. Res., 112, C03006, doi:10.1029/2006JC003743, 2007. 
JPL: QuikScat science data product user's manual (version 3.0), Jet Propulsion Laboratory Publ. D-18053, Pasadena, CA, 91 pp., available online: http://podaac.jpl.nasa.gov/DATA_CATALOG, 2006.

Katsaros, K. B., Forde, E. B., Chang, P., and Liu, W. T.: QuikSCAT facilitates early identification of tropical depressions in 1999 hurricane season, Geophys. Res. Lett., 28, 1043-1046, 2001.

Le Marshall, J., Leslie, L., Morison, R., Pescod, N., Seecamp, R., and Spinoso, C.: Recent Developments in the Continuous Assimilation of Satellite Wind Data for Tropical Cyclone Track Forecasting, Adv. Space Res., 25, 1077-1080, 2000.
Pickett, M. H., Tang, W., Rosenfeld, L. K., and Wash, C. H.: QuikSCAT satellite comparisons with nearshore buoy wind data off the US west coast, J. Atmos. Ocean. Tecnol., 20, 1869-1879, 2003.

Plant, W. J.: Effects of wind variability at low wind speed, J. Geophys. Res., 105(C7), 16 899-16910, 2000.

Stoffelen, A., de Haan, S., Quilfen, Y., and Schyberg, H.: ERS Scatterometer Ambiguity Removal Comparison, OSI SAF report, available online: http://www.knmi.nl/scatterometer/ publications/, 2002.

Wilks, D. S.: Statistical methods in the atmospheric sciences, Academic Press, 467 pp., 1995. 